\title{
From ignorance to denial about an orphan, but no rare, genetic disease: Ehlers-Danlos Syndrome (EDS type III)
}

\author{
Claude Hamonet ${ }^{1}$, Jean-David Zeitoun ${ }^{2}$ \\ 1. Medical School of Creteil, East University Creteil (UPEC), Paris, France. 2. Department of Physical Medicine and \\ Rehabilitation, Hôtel-Dieu de Paris, France.
}

Correspondence: Claude HAMONET. Address: Medical School of Creteil, Paris-East University Creteil (UPEC), 8 avenue du Général Sarrail, 94010 Créteil. Email: pr.hamonet@wanadoo.fr

Received: December 30, 2011

Accepted: April 4, 2012

Published: November 1, 2012

DOI : $10.5430 /$ jnep.v2n4p86

URL: http://dx.doi.org/10.5430/jnep.v2n4p86

\section{Abstract}

The development of medicine is increasingly based on biology and medical imaging keeps the doctor away from the bedside. In addition, both doctors and patients believe less and less in clinical medicine. This is compounded by poor application of evidence-based medicine and leads to give probative value to biological tests and, in particular, genetic tests. One can add the fragmentation of medical practice in specialties and subspecialties which hampers a comprehensive view of the patient. This and some medical prejudices, including a lack of confidence in the patient, explain that a poorly described disease, with multiple manifestations, without biological or radiological test, has very little chance of being recognized. This is the case of a multi painful hemorrhagic hypermobile syndrome with asthenia, called Ehlers-Danlos syndrome (EDS) which, despite its relative frequency, continues to be ignored by almost all of the medical profession. This leads to a delay in diagnosis of about 21 years for women and 15 years for men, after the onset of symptoms, and leaves in ignorance people with a genetically transmitted disease. Our approach relies on clinical observation of 612 cases that we have personally received in consultation at the hospital.

\section{Key words}

Ehlers-Danlos Syndrome, Genetic disease, Hypermobility, Hemorrhages, Asthenia, Proprioception disorders, Gastro-esophageal reflux

\section{I ntroduction}

On December 15, 1900 Edwards Ehlers, a Danish dermatologist, presented to the Danish Society of Dermatology and Syphilology ${ }^{[1]}$ a patient stating that he had never met a similar case and asking for help to understand.

He was a law student whose skin condition was remarkable for its fragility, its stretchability and the presence of numerous bruises, associated with events indicating that the cutaneous signs only were the emergence of a larger pathologic process.

He describes: hypermobility, instability bleeding, difficulty in walking and balance, sweating. A little later, in 1908 in Paris ${ }^{[2]}$, a French dermatologist presented the case of a patient with skin stretchability, a sign that seems to have fascinated 
him. Both observations were connected and Ehlers-Danlos syndrome was born ${ }^{[3]}$. In the medical culture to come, we note only two signs: hypermobility of joints and the stretchability of the skin. Both have captured the imagination of doctors because of the similarity with contortionists, which will unfortunately reduce an important clue for diagnosis to an amusing curiosity.

\section{Evolution of ideas, knowledge and medicine}

The development of rheumatology has produced an interest in this discipline for hypermobility, but calling it "benign" it reinforced the path implied by Danlos without enriching its symptomatology ${ }^{[4]}$.

On the other hand, geneticists have identified the role of the altered connective tissue, especially that of collagen and the transmission of an autosomal dominant trait ${ }^{[5]}$. But still so far they have not succeeded in producing a DNA test but only criteria of classifications whose reliability is being challenged by the increasing number of clinical observations. A consensus seems to settle in around three major types of Ehlers Danlos: the hypermobile form which is by far the most common one, the classical (type I-II) dominated by the skin signs, which is rare and the vascular (type IV) form with numerous arterial dilations, which is very rare.

This confusion adds to the discomfort of patients and families that gather different opinions about their disease, and often suffer from not being taken seriously or be mistaken for someone else. This concern becomes fear when they discover, often via the Internet, a form of "vascular EDS" ${ }^{6,7]}$ which is described as "lethal" with dramatic complications of arterial, intestinal and uterine ruptures.

\subsection{The current problem for patients and their families}

Strangely, the reputation of a rare disease has focused on this syndrome contributing thus to its exclusion from medical discussions and non-social recognition.

Doctors, misinformed (or uninformed) on symptoms of the syndrome overwhelmingly chose one of the following solutions (sometimes both):

1) Correlating symptoms to a well-known medical condition, often a hot topic of the moment in the medical literature and the media.

2) Rejecting the patient with a psychosomatic trends toward hysteria; this is summarized by this ritual formula which qualifies them, as reported by a large number of our patients, "it is in your mind!"

This exposes the patient to the harmful effects of iatrogenesis in the first case, humiliation and guilt in the second case.

\subsection{The true clinical identity of the syndrome}

Our approach relies on clinical observation of 612 cases that we have personally received in consultation at the hospital.

Instead of surprising, the multiplicity of symptoms from different organs which have in common that they consist of a loss of connective collagen tissue, is already a very important clinical orientation.

The narrowing of the syndrome to cutaneous and (or) joints forms and vascular forms, has had very negative consequences for the diagnosis and thus the detection of this genetic disease. Its frequency is certainly above the threshold of 2000 births per year which is the criterion for rare diseases in France.

Thus, a general practitioner for which we diagnosed a case, has discovered in the following year, 13 others affected patients. 
The fact that life expectancy (excluding the risk of iatrogenic effect!) is not modified is consistent with a growing population.

When we realize the suffering and obstacles our patients are faced with, we discover a novel concept that has to be known that of a real public health problem posed by all unidentified persons that are not or poorly treated and that transmit the disease without knowing it.

The 10 clinical signs leading to diagnosis of 612 cases ${ }^{[7]}$ :

1) Diffuse periarticular pain (98\%), muscle pain (80\%), skin (confused with neuropathic) pain, abdominal pain (77\%), thoracic pain (66\%), genital pain, migraine (87\%), all variables, refractory to painkillers.

2) Fatigue and decreased level of consciousness (98\%) with fits of drowsiness and feelings of exhaustion, even upon awakening.

3) Hypermobility of joints (96\%) which is not always spectacular and decreases with age (test Beighton less than 4/9).

4) Fragility of the skin (97\%) which can take various forms: frequent excoriations (83\%), delayed and impaired wound healing (73\%), early and (or) extensive stretch marks (74\%), a soft and apparently smooth feeling (74\%). The stretchability is absent in $31 \%$ of cases and is therefore not necessary for diagnosis despite persistent prejudice.

5) The hemorrhagic syndrome (91\%) linked to the fragility of vessels is expressed by the occurrence of quasi-spontaneous bruising and hematoma, gums, nosebleeds, very heavy periods, bronchial or gastrointestinal bleeding possibly exposing patients to complications during endoscopic procedures.

6) Proprioceptive disorders (98\%) with problems of perception and control of body movements that are expressed by subluxations, sometimes combined with sprains, falling of objects or people (frames door, especially "sign on the door"), falls, blunders (falling objects), pseudo paralytic presentations and (or) transient ignorance of one body part.

7) Constipation (72\%) can be severe and pseudo occlusive conditions leading to untimely surgical interventions.

8) The gastro-esophageal reflux (76\%) with its attendant effect on the airways.

9) Dyspnea (83\%) occurring after insignificant efforts, and disrupting the voice.

10) Sensations of respiratory blockages (61\%) occurring unexpectedly.

A family history of similar cases, even less severe especially in men, is a major diagnostic feature.

These 10 signs are not always all present, but the combination of five of them seems sufficient for the diagnosis and to initiate appropriate management.

\section{Diagnoses most often mentioned before that of Ehlers-Danlos syndrome:}

Results of a survey conducted on 135 people with Ehlers-Danlos syndrome:

- Mental disorders (“it's in your mind,” "hysteria”, "it is psychosomatic”): 88 (65\%) 
- Rheumatologic disease (except fibromyalgia): 59 (44\%)

- Fibromyalgia: 47 (35\%)

- $\quad$ Neurological disease: 42 (31\%) (Multiple sclerosis: 17 (13\%))

- $\quad$ Marfan syndrome: 24 (18\%)

- Child maltreatment: 20 (15\%)

- Crohn's disease or celiac disease: 19 (14\%)

\section{Prognosis and evolution}

Prognosis is a legitimate concern for those patients who compare their status to that of a degenerative disease.

In fact, it is unpredictable and varies from person to person, even in the same family. We identified certain internal factors (female endocrinology, there are $81 \%$ of women in our series of patients) or external (trauma, climate) as the source of increasing symptoms.

\section{Ethical considerations}

This unhappy saga of Ehlers-Danlos leads to several discussions on health practices.

1) Lack of listening from the doctor

The views of patients we interviewed were unanimous. They are not listened to, they are not believed, they are not taken seriously, especially as imaging studies and biology, which are widely prescribed, are normal (especially the mythical MRI). Almost all doctors cannot believe that you have major pain with a normal MRI. This holy test in the minds of doctors, just like the test of God's justice in the middle Ages, is used to "confuse" the patient and to lead him to psychiatry.

It is not only questioning, a critical time of the clinical examination, which fails ("listen to your patient, he is telling you the diagnosis” said Osler). The clinical examination itself, the skin in particular, is essential.

2) The importance of biology

What hampers the identification of Ehlers-Danlos syndrome is the absence of genetic and biological argument, except for the demonstration of a COL3A1 gene mutation in the vascular form. Yet the diagnosis is obvious on the clinical grounds we have described. The confusion between evidence-based medicine and the need for a biological or imaging proof has a devastating effect.

This is probably a sign of a decline in the bedside medicine which seems to be very serious, especially for the poorest countries which lack technical equipment.

3) The power of dogma and beliefs in medicine

Classifications have been the basis of medical thought since the 18th century with the development of diseases classification systems inspired by botanists by two doctors: François Boissier de Sauvages in France ${ }^{[9]}$ and Carl Linné in Sweden ${ }^{[10]}$. This is useful to give a diagnosis but, in the absence of frequent confrontations with the clinical reality, this turns out to be an obstacle. It is currently the case for the EDS, for which the geneticists only have made classifications, with restricted criteria that are inappropriate to the knowledge of current clinical syndrome. This leads to the refusal to include some of the symptoms (digestive, respiratory, dysautonomic, gynecological, ophthalmology, oral) and excluding patients from dispositions facilitating access to social care, in 
France anyway. A complete revision of the symptomatology of the syndrome, based on the testimony of patients, is urgently needed.

4) The fragmentation of knowledge in medicine

The sub division of medical practice in specialties centered on an organ does not facilitate the diagnosis of a condition that, specifically, involves several organs. Each specialty has its list of diseases to diagnose. The Ehlers-Danlos syndrome has taught us a lot about this question since many of our patients ended up with "diseases" such as: Gougerot-Sjögren's disease, asthma, endometriosis, hypothyroidism, each of them having shared items to the EDS. Curiously, this difficulty in gathering the symptoms led to referring to psychiatry clinic without any convincing argument of any for three frequent diagnoses eventually chosen: depression, bipolar syndrome and hysterical conversion.

5) The role of the Internet should be highlighted

All patients have access to web search engines more and more efficient, with all the information in it, whether good or bad, without the means to sort out and prioritize data. Another related phenomenon is that of the Forum that allows exchanges between the patients and the flow of information accompanied by personal opinion that may create confusion, especially when doctors do not agree with each other.

6) One last point we may emphasize is the negativity of some of the doctors' speeches. It is unacceptable that a patient may say “I feel worse when I get out of the doctor's office than when I entered.” Regarding specifically the Ehlers-Danlos syndrome, it is not acceptable, either, the doctor can oppose a denial to the patient: "I do not believe it" or hide behind ignorance of the question: "I do not know" which is interpreted as a sign of disinterest.

\section{Conclusion}

Ehlers-Danlos syndrome, especially in its hypermobile form, is a clinical reality which is a source of suffering and disability. Its polymorphism and its variability bother and puzzle the doctors who adopt positions of rejection and distrust towards their patients. This attitude is indicative of a medical practice which is locked in an overly technically exploited specialization. The human link between the patient and the physician, based on mutual trust, is at stake, so as is clinical medicine.

\section{References}

[1] Ehlers E. Cutis laxa, Neigung zu Haemorrhagien in der Haut Lockerung merher Articulationen tendance aux hémorragies de la peau, relâchement de plusieurs articulations (Case for diagnosis) », Société danoise de Dermatologie, 15 décembre m. Dermat. Woch. VIII, p. 173. 1900,

[2] Danlos A. Un cas de Cutis laxa avec tumeurs par contusions chroniques des coudes et des genoux (xanthome juvénile pseudo-diabétique de MM Hallopeau et Macé de Lépinay) Communication à la Société Française de Dermatologie et de Syphiligraphie, Paris, .2-06 Février 1908.

[3] Miget A. Le syndrome d'Ehlers-Danlos, thèse de doctorat en médecine, Faculté de Méde.cine de Paris, 1933.Halpern SD, Ubel PA, Caplan AL. Solid-transplantation d'organes en matière de VIH chez les patients infectés. N Engl J Med. Juillet. 2002 ; 347 (4): 284-7.

[4] Graham R., Bird RA, Child A. The revised (Brighton 1998) criteria for the diagnosis of benign joint hypermobility syndrome (BJHS).The Journal of Rheumatology. 2000 Jul; 27 (7): 1777-9. PMid:10914867

[5] Germain D.P. le syndrome d’Ehlers-Danlos, aspects cliniques, génétiques et moléculaires. 1995; 122(4): 187-204,

[6] Pepin M, Schwarze U, Superti-Furga A, Byers PH. Clinical and genetic features of Ehlers-Danlos syndrome type IV, the vascular type. N Engl J Med. 2000; 342: 673-80. PMid:10706896 http://dx.doi.org/10.1056/NEJM200003093421001

[7] Franck M., Syndrome d'Ehlers Danlos vasculaire, la Revue du praticien. 2009; 59: 461-469. 
[8] Beighton P, De Paepe A., Steinman B., et al. Ehlers-Danlos syndrome: revised nosology, Villefranche 1997, Am. J. Med, Genet, 1998; 77: 33-7. http://dx.doi.org/10.1002/(SICI)1096-8628(19980428)77:1<31::AID-AJMG8>3.0.CO;2-O

[9] Hamonet C, Gilles Mazaltarine G., et al. Syndrome d’Ehlers-Danlos (SED), Nouvelle description clinique, Apports de la Médecine Physique et de la Réadaptation. Etude prospective de 612 cas. Communication au 26ème Congrès de la Société française de Médecine Physique et de réadaptation, Nantes, 15 Octobre 2011.

[10] Hamonet C, Mazaltarine G., Deparcy D., Ehlers-Danlos un syndrome ignoré à évoquer en priorité devant l'association : fatigue, douleurs, troubles proprioceptifs. Apports spécifiques de la médecine de réadaptation, Lett. Med.Phys. Réadapt. 2011; 27: 196-202

[11] Boissier de Sauvages de Lacroix F. Nosologie méthodique dans laquelle les maladies sont classées suivant le Système de Sydenham et l'Ordre des botanistes, augmenté de quelques notes par M. Nicolas chirurgien gradué, 1771, Paris.

[12] Pulteney Richard et Linné C. traduction par Millin de Grandmaison L.A., Revue générale des écrits de Linné, 1789, Paris. 